\title{
I ncidence of Nocardia species in raw milk collected from different localities of Assiut City of Egypt
}

\author{
Nahed Mohamad Wahba ${ }^{1}$, Neveen Abdel Ghany Elnisr ${ }^{1}$, Nagah Mohamad Saad ${ }^{2}$, \\ Saad Mohamad $\mathrm{Nasr}^{2}$ and Walaa Mahmoud $\mathrm{Ali}^{1}$ \\ 1. Animal Health Research Institute, Assuit city-Egypt \\ 2. Faculty of Veterinary Medicine, Assuit University, Assuit city-Egypt \\ * Corresponding author email : nahedmw@yahoo.com \\ Published online at www.veterinaryworld.org on 25-03-2011
}

\begin{abstract}
This study aimed to isolate and enumerate Nocardiae from the examined raw milk samples. 240 random milk samples were collected from cows, buffaloes, sheep and goats from different localities in Assiut city- Egypt. The incidences of Nocardia spp. were $47.8,43.3,53.3$ and $66.7 \%$ with average counts of $3.8 \times 10^{4}, 4.5 \times 10^{4}, 1.4 \times 10^{4}$ and $7.6 \times 10^{3} / \mathrm{CFUmL}$ of the examined samples, respectively. Pathogenicity of the isolates was also studied. $N$. otitidiscavarium and $N$. brasiliensis caused sudden death of rats while, $N$. farcinica and $N$. carnea strains were non pathogenic. Other species caused several lesions. It was concluded from the study that, Nocardia species are existed in retailed and fresh milk of different farm animals. Most of the isolated strains were highly pathogenic to rats. Consequently, preventive measures should be taken to protect consumers from being infected.
\end{abstract}

Keywords: Nocardia species, Raw milk,Incidence, Pathogenicity, Zoonosis.

\section{I ntroduction}

Nocardia species are one of the worldwide bacterial infections and has been implicated in the pathogenesis of pulmonary nocardiosis, brain abscesses, enteritis, arthritis, and endocarditis in all infected humans, including children and immune suppressed patients (Maria Bernadete et al., 2007). Infections due to Nocardia spp. are generally acquired through inhalation, trauma and ingestion (Dwight et al., 2004 and Martínez et al., 2008). The seriousness of the disease returns to the fact that clinical diagnosis is difficult due to non-specific manifestations (Saubolle and Sussland, 2003) and contamination of soil from the infected patient who plays an important role in wide spreading of the pathogens (Pisoni et al., 2008).

Economically, the most important host is the dairy cow. High incidence of bovine mastitis (due to nocardia infection) has been reported all over the world (Pisoni, 2008). Presence of Nocardia spp. in raw milk is not surprising as they are soil-borne aerobic actinomycetes (Saubolle and Sussland, 2003), and may contaminate milk during milking, handling, storage and transportation (Schinger, 1994). The present work investigated the existence of Nocardia species in different raw milk (cows, buffaloes, sheep and goats) as well as their pathogenicity.

\section{Material and Methods}

Milk samples: A total of 240 random samples of raw milk were collected during year 2009 from different localities in Assiut city, Egypt. The samples included cow's milk (90), buffalo's milk (90), sheep's milk (30) and goat's milk (30). Cow and buffalo's milk samples were collected from dairy farms, dairy shops and street vendors ( 30 samples of each).

I solation of Nocardia species: One $\mathrm{mL}$ of each milk sample was aseptically inoculated into BushnellHaas broth (Difco) (Schaal, 1972). The inoculated tubes were incubated at $37{ }^{\circ} \mathrm{C}$ for 2-7 days and examined every 2 days. A loopfull from the incubated broth cultures was streaked onto plates of nocardia media (Difco) and incubated at $37{ }^{\circ} \mathrm{C}$ for 2-7 days (Gordon et al., 1974).

I dentification of the isolates: Suspected colonies were identified morphologically and microscopically (Brown and McNeil, 2003). Biochemical tests and confirmation of species were applied according to Cowan and Steel, (1974).

Enumeration of Nocardia species (APHA, 1992): $10 \mathrm{~mL}$ of each prepared sample were added to $90 \mathrm{~mL}$ of sterile saline solution, mixed to make a dilution of $1 / 10$, from which ten fold serial dilutions were prepared. $0.1 \mathrm{~mL}$ from each dilution was transferred and spread over a dry surface of nocardia agar plates (Difco). The plates were incubated at $37{ }^{\circ} \mathrm{C}$ for 2-7 days and the numbers of Nocardia spp./mL were calculated.

Pathogenicity of the isolated Nocardia strains: 
Incidence of Nocardia species in raw milk collected from Different localities of Assiut City of Egypt

Table-1: Incidence of the isolated Nocardia spp. recovered from milk samples

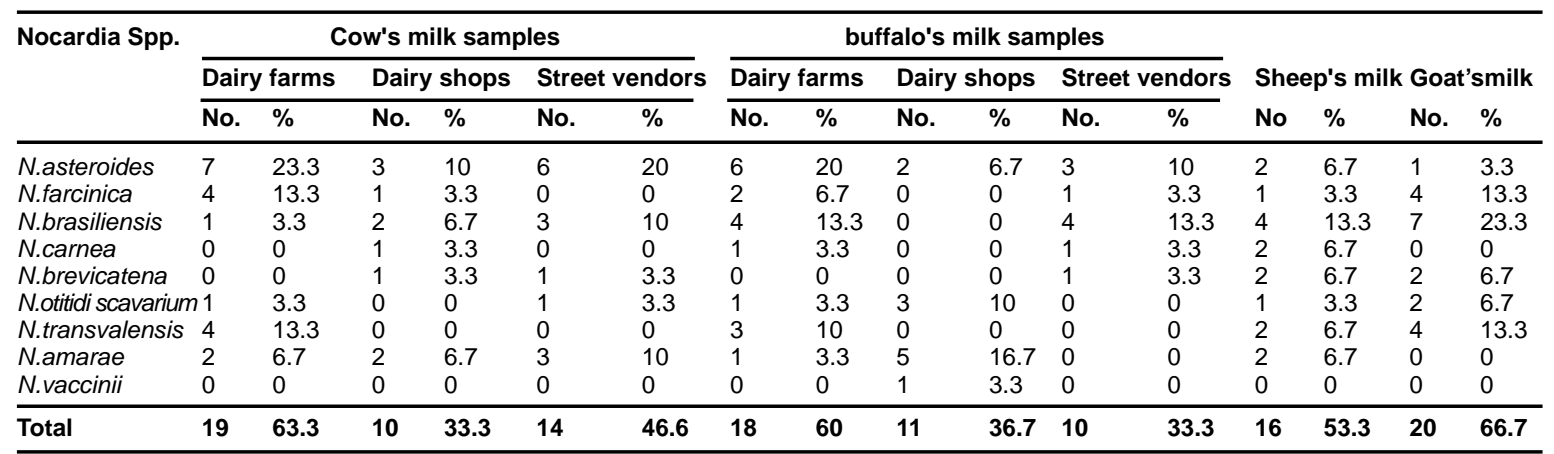

Animals: 30 male Spargue Dawley Albino rats (from 9 to 12 weeks old, weighing about $250 \mathrm{gm}$ ) were obtained from the Animal House, Fac. Medicine, Assiut Univ.

Strain culture: Isolated Nocardia species (9 strains) were sub cultured into nutrient broth and incubated at $37^{\circ} \mathrm{C}$ for $48 \mathrm{~h}$. Ten fold serial dilutions up to $1 / 10^{10}$ were prepared; plate counts revealed that such broth cultures contain approximately $10^{9} \mathrm{CFU} / \mathrm{mL}$.

The intraperitoneal inoculation of rats: 27 rats were I/P inoculated with nine different Nocardia species (3 rats for each strain). Each rat was injected $\mathrm{I} / \mathrm{P}$ with one $\mathrm{mL}$ of the broth culture. Another 3 rats were kept as a control (Pier et al., 1961). Two weeks later, all animals that survived were sacrificed and subjected to PM inspection and histopathology according to Bancroft et al., (1996). The representative lesions were cultured for reisolation of the inoculated Nocardia species.

\section{Results}

Nocardia spp. were isolated from cow's, buffalo's, sheep and goat's milk samples in percentages of 47.8 , 43.3, 53.3 and $66.7 \%$ and average counts of $3.8 \times 10^{4}$, $4.5 \times 10^{4}, 1.4 \times 10^{4}$ and $7.6 \times 10^{3} \mathrm{CFU} / \mathrm{mL}$, respectively. $19(63.3 \%)$ out of 30 cow's milk samples from dairy farms, were found to be contaminated with Nocardia spp. with average count of $1.3 \times 10^{4} \mathrm{CFU} / \mathrm{mL}$. Lower percentages $(46.7,33.3 \%$ ) were found in milk samples from street vendors and dairy shops with average counts of $7.4 \times 10^{3}$ and $2.6 \times 10^{4} \mathrm{CFU} / \mathrm{mL}$, respectively. In buffalo's milk samples, the highest incidence $(60 \%)$ was obtained from milk samples from dairy farms. However, the incidences in buffalo's milk samples from dairy shops and street vendors were $36.7 \%$ and $33.3 \%$ with average counts of $1.2 \times 10^{4}$ and $5.9 \times 10^{3}$ CFU /mL, respectively. Nocardia spp. could be isolated from sheep and goat's milk samples in percentages of 53.3 and $66.7 \%$ and average values of $1.4 \times 10^{4}$ and $7.6 \times 10^{3} \mathrm{CFU} / \mathrm{mL}$, respectively. N. asteroides was the highest frequency distributed species in all examined milk samples; the distribution of the species was illustrated in Fig. 1. PM inspection showed that $N$. asteroides caused severe congestion in intestine, brain, parynchymatous and genital organs with clear enlargement of testis. $N$. brasiliensis, $N$. brevicatena, $N$. otitidis-cavarium, $N$. transvalensis, and $N$. vaccinii were also virulent causing similar lesions. $N$. otitidiscavarium and $N$. brasiliensis caused sudden death. On the other hand, N. farcinica and N. carnea were non pathogenic. Histopathological studies showed inflammatory edema between the villi of the intestine and increase of the goblet cells (Fig. 2A). Liver showed degeneration of the hepatic cells especially in the portal area (Fig. 2B and C). Lung showed degeneration of the bronchial epithelium, congestion of the bronchial blood vessels and thickening in the interalveolar septa with inflammatory cells (Fig. 3A). Vaccular degeneration in the tubular epithelium of the kidneys (Fig 3B), pertubular edema with tubular degeneration of the testis (Fig. 3C) and congestion in the cerebral blood vessels were noticed (Fig. 3D).

\section{Discussion}

In the current study the incidence of Nocardia spp. in milk samples was considered higher than other previous studies (Abdel-Fattah, 1996 and Seddek, 2001). This higher incidence may be attributed to the fact that they are wide spread in nature. They may be introduced into the udder by insertion of cannula, contaminated preparations, drug mixture and tips of injectors (Seddek, 2001). The extensive use of antibiotics in the treatment of mastitis increased the incidence of Nocardia infection (Pisoni et al. 2008). Furthermore, the lack of hygienic measures and poorly sanitized dairy farm equipments constitute the major 

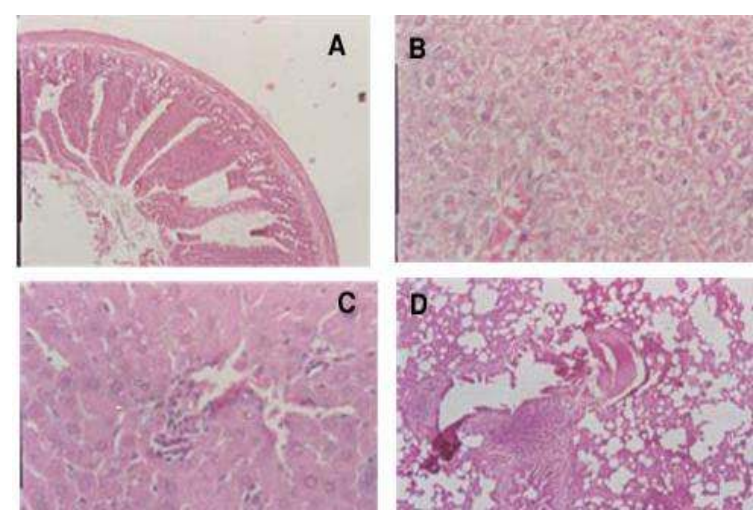

Figure-1. I ntestine (A), liver (B and C)) and lung (D) of Nocardia infected rats (H\&Ex10).

sources of contamination of different types of milk. The highest incidence of Nocardia spp. in goat's milk associated with poor hygienic nomadic rearing conditions in housing and in the milking parlous (Contreras et al., 2002). Some environmental factors facilitate multiplication of these organisms in milk such as hot and wet weathers. Contamination of soil from the infected patient plays an important role in wide spreading of the pathogens (Pisoni et al., 2008). Moreover, low income people use raw milk in preparation of some products increasing the potential risk of infections spread among community elements.

Pathogenic Nocardiae are saprophytes in many climates, soils and water, either as endogenous microbiota or as contaminants (Dwight et al., 2004) so, it is very important to study the severity and pathogenicity of these species that have been isolated from milk samples. Intraperitoneal inoculation of the isolated strains revealed that $N$. otitidiscavarium and $N$. brasiliensis caused sudden death of the inoculated rats. Other species were also virulent causing several lesions. In other experimental animal models, Malik and Bakshi, (2002) found that $N$. asteroides, $N$. farcinica, N. brasiliensis and N. otitidiscaviarum were the most pathogenic species that caused infections in most laboratory animals. Despite $N$. farcinica was avirulent in this study, it is claimed to be the etiology of human nocardiosis (Rivero et al., 2008) because of its tendency to dissemination and its resistance to antibiotics (Torres et al., 2000 and Hitti and Wolff, 2005). So, further investigations should be conducted to study the virulence of different nocardia strains. It was concluded that the prevalence of Nocardia spp. in milk samples was high. All recovered Nocardiae were pathogenic strains except $N$.farcinica and $N$. carnea. So, proper cleaning and sanitizing of all dairy utensils
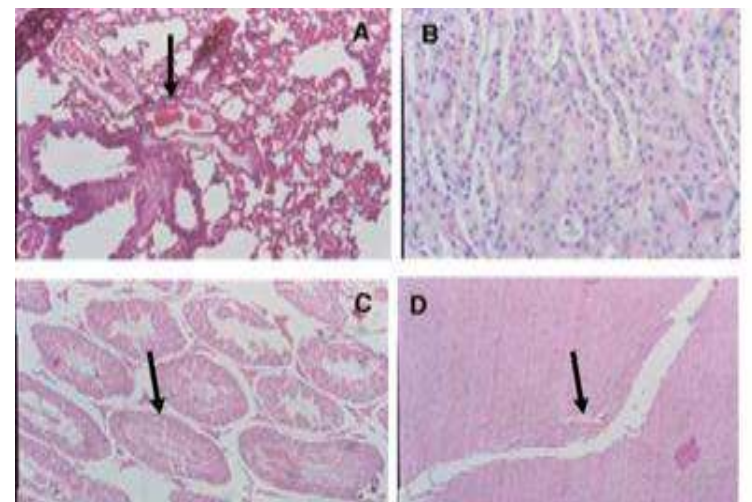

Figure-2. Lung (A), kidney (B), testis (C) and brain (D) of Nocardia infected rats (H\&Ex 10).

and equipment used in milk production was essential. The extensive use of antibiotics in the treatment of mastitis should be avoided as this may increase the incidence of Nocardial infection. Moreover, persons who handle milk should be periodically examined to prevent transmission of Nocardia spp. by food handlers into the food chain.

\section{Acknowledgements}

Authors are sincerely grateful for the great help provided by members of Food Hygiene and Control Department, Faculty of Veterinary Medicine, Assuit University.

\section{References}

1. [A P H A] American Public Health Association (1992): Compendium of Methods for the Microbiological examination of Foods, $2^{\text {nd }}$ Ed Washington, DC: American Public Health Association.

2. Abdel-Fattah, A. M. (1996): Epidemiological properties of pus-forming bacteria. Assiut Vet MedJ., 34(68): 149-155.

3. Bancroft, J. D.; Stevens, A. and Turner, D. R. (1996): Theory and practice of histological techniques $4^{\text {th }} \mathrm{Ed}$ Churchill Living Stone, New York Edinburgh. Madrid, Sanfrancisco.

4. Brown, J. M. and McNeil, M. M. (2003): Nocardia, Rhodococcus, Gordonia, Actinomadura, Streptomyces and other aerobic actinomycetes, In: Murray PR, Baron EJ, Pfaller MA, Tenover FC, and Yolken RH, (Ed). Manual of Clinical Microbiology, $8^{\text {th }}$ Ed. 502-531. American Society for Microbiology, Washington, D.C.

5. Contreras, A.et.al. (2002): The role of intramammary pathogens in dairy goats. Epidemiología y Enfermedades Infecciosas, Murcia, Spain.

6. Cowan, S.T. and Steel, K.J. (1974): Manual for Identification of Medical Bacteria. $2^{\text {nd }}$ ed Cambridge, Cambridge Univ. press.

7. Dwight C. Hirsh, et.al. (2004): Filamentous bacteria: Actinomyces, Nocardia, Dermatophilus and Streptobacillus. Veterinary Microbial. $2^{\text {nd }}$ ed. Pp. 218-220.

8. Gordon, M.A. (1974): Aerobic pathogenic Actinomy cetaceae. In Lennette, Spaulding and Truant (eds), Manual of 
clinical microbiology. American Society for Microbiology, Washington. D.C.Pp.175-188.

9. Hitti, W. and Wolff, M. (2005): Two cases of multidrug resistant Nocardia farcinica infection in immunosuppressed patients and implications for empiric therapy. Eur. J. Clin. Microbiol. Infect. Dis. 24(2): 142-144.

10. Malik, B. S. and Bakshi, C. S. (2002): Nocardia. In, Objective and Short Answer Questions in Veterinary Bacteriology and Mycology. $2^{\text {nd }}$ Ed. C.B.S. New Delhi. Chapter 25: 152-153.

11. Maria Bernadete, F. C.; Marcio, F. C.; Nelson, S. P, Severo, B. S. and Luizcarlos S. (2007): Nocardial infections: report of 22 cases. Rev. Inst. Med. Trop. 49 (4).

12. Martínez, R.et.al. (2008): Pulmonary nocardiosis: risk factors, clinical features, diagnosis and prognosis. Curr. Opin. Pulm. Med. 14(3): 219-227. [PubMed]

13. Pier, A. C.; Willers, E. H. and Mejia, M. J. (1961) N.asteroides as mammary pathogen of cattle. I- The disease in cattle and the comparative virulence of 5 isolates. Amer. J. Vet. Res. 7: 698-703.

14. Pisoni, G.et.al. (2008): Short communication: outbreak of N.neocaledoniensis mastitis in an Italian dairy herds. $J$. Dairy Sci.91(1): 136-139.

15. Rivero, A. et.al. (2008): Successful long-term treatment with linezolid for disseminated infection with multiresistant Nocardiafarcinica. Infec. 36(4): 389-391.

16. Saubolle, M. A. and Sussland, D. (2003): Nocardiosis: review of clinical and laboratory experience. J. Clin. Microbiol.41: 4497-4501.

17. Schaal, K. P. (1972): Zur mikrobiologisher Diagnostik der Nocardiose. Zentralbl. Bakteriol. Parasitenkd. Infektionskr. Hyg. IAbt. Orig. 220: 242-246.

18. Schinger, M. (1994): Personal communication. Cited by Schuh, G.; Schoder, H.; Weissen Book and Hotter, H. (1994) on the occurance of Nocardial mastitis and resistancy significant mastitis causing pathogens in Austriain in dairy herds. $6^{\text {th }}$ ed. Sci. Cong. 22 Nov. fac. Vet, Med, Assiut Egypt.

19. Seddek, S. R. (2001): Isolation of Nocardia organisms from soil and mastitic milk of dairy cows (Friezian and Holestein) on different media on some governomental farms in Assiut governorate. Assiut Vet. Med. J. 46(92): 72-82.

20. Shawar, R. M.; Moore, D. G. and LaRocco, M. T. (1990): Cultivation of Nocardia species on chemically defined media for selective recovery of isolates from clinical specimens. J. Clin. Microbial. 28(3):508-512.

21. Torres, O. H. et.al. (2000): Infection caused by Nocardia farcinica: case report and review. Eur. J. Clin. Microbiol. Infect. Dis. 19:205-212. 